\title{
Stroke patients care by the Senegal-National Emergency Medical services: retrospective study over 22 months
}

\begin{abstract}
Introduction: Stroke according to the WHO (World Health Organization) is a sudden deficit of focal brain function with no apparent cause other than a vascular cause. It is a major public health problem. It is the first cause of motor disability, second cause of cognitive disability and third cause of mortality in the world.

Material and method: It is a retrospective and descriptive study of a period of 22 months (January 1, 2016 to October 30, 2017) conducted in the national Emergency Medical Services of Dakar (Senegal). According to our study criteria, 343 patients were collected.

Results: The mean age of the patients was 64.2 years (extremes of 17 and 104 years). Men represented 54.22\% (sex ratio $\mathrm{M} / \mathrm{W} 1.8$ ). Dakar represented the main provenance of our patients $(79.30 \%)$. Hypertension was the main risk factor $(50 \%)$. Acute headaches were the main warning sign (13.41\%). An echocardiography was performed in 59 patients; complete tachyarrhythmia by atrial fibrillation represented $30 \%$ of the ECG. The CTscan was performed for 201 patients $(61 \%$ of ischemic stroke, 37.5\% hemorrhagic and $1.5 \%$ of transient ischemic attack). The medevac represented $53.93 \%$. Transportation was made essentially by the emergency medical services; home interventions were the most represented. The mean time for intervention by the emergency medical services was 134.71 minutes. Fann Hospital was the main host structure (45.49\%). The care (of the emergency medical services) included, among others, intubation (4.8\%), monitoring, oxygen therapy, urinary catheter and medical treatment. We noticed $20.40 \%$ of deaths in our series, due essentially to neurological complications.

Conclusion: Stroke is a major public health problem. Difficulties are sometimes encountered in the care and the research of an appropriate host structure. The purpose of the pre-hospital care is to intervene as soon as possible while making a clinic diagnosis by performing forthwith a brain CT-scan in order to optimize the care and improve the prognostic of stroke patients.
\end{abstract}

Keywords: stroke, Senegal, care, prognostic
Volume IO Issue I - 2020

\author{
Marième Soda Diop-Sène,' Ousmane Cissé,' \\ Khalifa Ababacar Mbaye,' Rokhaya Diagne,' \\ Ahmadou Bamba Mbodji,' Ngor Side \\ Diagne, ${ }^{1,2}$ Papis Sissoko,' Kamadore Touré,' \\ Moustapha Ndiaye, ' Amadou Gallo Diop' \\ 'Neurosciences Clinic Ibrahima Pierre Ndiaye, FANN National \\ Teaching Hospital Center, Senegal \\ ${ }^{2}$ Department of Physical Medicine and Rehabilitation, Fann \\ National Teaching Hospital Center, Senegal
}

Correspondence: Marième Soda Diop-Sène, Neurosciences Clinic Ibrahima Pierre Ndiaye, FANN National Teaching Hospital Center, Dakar-Senegal, Email dmariemesod@gmail.com

Received: December 26, 2019 | Published: January 20, 2020

\section{Introduction}

Stroke is a public health problem, the first cause of motor disability, second cause of cognitive disability and the third cause of mortality in the word. ${ }^{1}$ That represents 10 millions people in the word, among which $10 \%$ having less than 45 years old. ${ }^{2}$

In 10 years, there has been a real therapeutic revolution with the demonstration of the efficiency of fibrinolysis by rt-PA ${ }^{3}$ in cerebral infarction on one hand and on the other hand in the multidisciplinary intra and inter-hospital chain leading to the intensive care structure called the Neurovascular Intensive Care Unit (NVICU), ${ }^{4,5}$ The initial management of stroke involves many stakeholders both in the prehospital and intra-hospital stages.

According to the literature, most patients with ischemic stroke arrive within the 3 hours and $30 \mathrm{~min}$ after the onset of symptoms, giving time to gather all the necessary conditions for the administration of thrombolysis..$^{1,2}$ This is why, there is a real need for information specially through public awareness campaigns.
The main objective of our study was to assess the contribution of the national Emergency Medical Services (EMS) in the overall care of stroke patients; and secondly, as specific objectives, to assess the response time, access to the brain CT-scan, the search for places in specialized or appropriate departments, and morbimortality.

\section{Methodology}

It is a retrospective and descriptive study over a period of 22 months from January 1, 2016 to October 30, 2017, led in close collaboration with the Neurology Department of Fann Teaching Hospital and the national EMS. Calls received are recorded at the Call Reception and Regulation Centre by the Asterick application. These files are stored in an electronic folder which constitutes the PostgreSQL base, completed by the EMS file (handwritten) after intervention. Data extraction was performed by pgAdmin. From that software, files were established where the data were collected.

Were included all the patients that, during the study period, have benefited from, whether: 
- $\quad$ Regulation by the national Emergency medical services

- Transportation by the Emergency medical services with a confirmed recent stroke from the brain CT-scan

Were excluded:

- $\quad$ Patient with old stroke

- $\quad$ Stroke patient with unusable record

- $\quad$ Patient whose brain CT-scan was not confirming a stroke

\section{Results}

The mean age of patients was 64.2 years with extremes of 17 and 104 years.

The age group 60-69 years was the most representative with $22.74 \%$ (Table 1). Our study has found 186 men (54.22\%) against 157 women $(45.77 \%$ ) or sex ratio M/W of 1.18. Dakar represented the main provenance of our patients with $79.30 \%$ and $1.16 \%$ coming from the sub-region (Table 1). On the clinical plan, 46 patients or $13.41 \%$ had a Glasgow score of 8 or less and an hemicorporeal deficit was found in $51.31 \%$ of our patients (Table 2).

Table I Repartition according to neurological signs

\begin{tabular}{llll}
\hline Neurological signs & & Number & Percentage \\
\hline & GCS $\leq 8$ & 46 & 13,41 \\
Conscience & GCS: $9-12$ & 47 & 13,70 \\
& GCS: 13-15 & 251 & 73,17 \\
& Myosis & 6 & 1,74 \\
& Mydriasis & 4 & 1,16 \\
Pupils & Anisocoria & 4 & 1,16 \\
& Normal & 330 & 96,20 \\
Hemicorporeal deficit & & 176 & 51,31 \\
Language disorders & & 55 & 16,03 \\
Facial paralysis & & 22 & 6,41 \\
Convulsive seizures & & 16 & 4,66 \\
Paraparesia & & 5 & 1,45 \\
\hline
\end{tabular}

\section{GCS Glasgow Coma Scale}

Only 201 patients have benefited from CT-scan or $58.60 \%$. We have noticed $61 \%$ of ischemic stroke and $37.50 \%$ of hemorrhagic stroke, and three patients presenting a transient ischemic attack had a normal brain CT-scan or $1.50 \%$ of the cases (Figure 1\&2). Fifty-nine patients had performed an ECG or $17 \%$ and the cardiac arrhythmias by atrial fibrillation represented $30 \%$ of the ECG and in $10 \%$ of the cases, the ECG was strictly normal (Table 3 ).

Medical evacuations (MEDEVAC) generally represented 53.93\% of the reasons for intervention (Table 4). In our series $55.97 \%$ of transportation were performed by the EMS of Dakar and in $24.78 \%$ of the cases there was not transportation (Table 5).
Table 2 Electrocardiographic signs

\begin{tabular}{llll}
\hline Electrocardiographic signs & Number & Percentage \\
\hline Tachyarythmia (atrial fibrillation) & 15 & 30,6 \\
Hemiblock & & 4 & 6,77 \\
RBBB & Complete & 2 & 3,39 \\
& Incomplete & 4 & 6,77 \\
AV Block & Type I & 3 & 5 \\
Ischemia or necrosis signs & 5 & 1,70 \\
Hypertrophia & & 5 & 8,47 \\
Extrasystole & & 4 & 6,47 \\
Normal ECG & & 6 & 10 \\
Total & 59 & 100
\end{tabular}

RBBB Right bundle branch block $\quad$ AVB Atrioventricular block

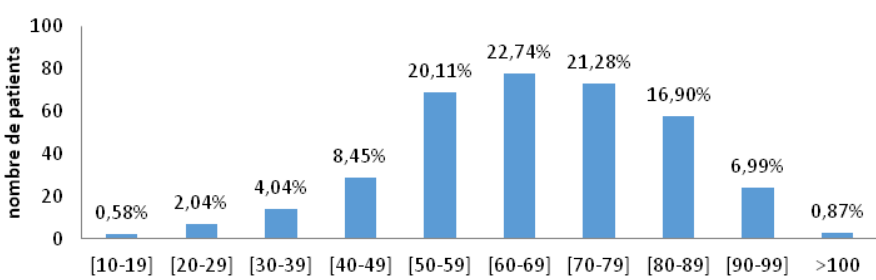

Figure I Evaluation of number of cases according to age group.

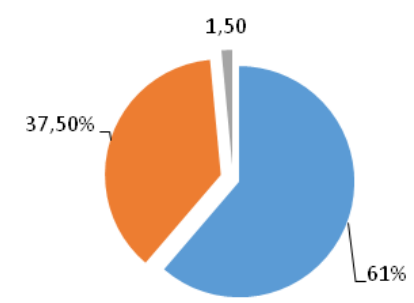

$\because \mathrm{AVCI}$

$\triangle \mathrm{AVCH}$

- SCANMER NORMAL

Figure 2 Repartition according to CT results.

Home interventions represented the first intervention site (32.06\%) and health facilities came in second position with $25.65 \%$ (Table 6). Sixty-five percent of our interventions were secondary interventions. The EMS arrived on average $15 \mathrm{~min}$ after the warning call in the agglomeration of Dakar while in the outskirts or suburbs, it took 26 min. (Figure 4). The EMS of Dakar took 32 min between home and intervention site. The mean time of the intervention by the EMS of Dakar was $134.71 \mathrm{~min}$

In our series, 211 patients or $61.51 \%$ of the patients have been evacuated in health facilities. Fann Hospital was the main host structure with $45.49 \%$ of our patients received (Figure 3). All the patients transported by the EMS or $208(60.93 \%)$ had been installed in a semiseated position at a $30^{\circ}$ angle. Among the patients transported, only 10 patients or $4.80 \%$ had benefited from an orotracheal intubation due to neurological complications (Glasgow of 8 or less). For the monitoring 
of vital functions, a scope had been installed for all our transported patients. The patients transported by the EMS had benefited from an oxygen-therapy on neurological $(10.57 \%)$, breath $(2.40 \%)$ and hemodynamic (1.92\%) basis. Those presenting clinical complications $(14.89 \%)$ had benefited from urinary catheter. In our series $13 \%$ of the patients presented hypertensive crisis but the blood pressure was strictly respected during transportation. All the transported patients or $60.93 \%$ had benefited from an intravenous access with an isotonic saline serum. The number of patients presenting an ischemic stroke was of $61 \%$ but none had thrombolysis.

Table 3 Repartition according to reason of calls

\begin{tabular}{lll}
\hline Reasons of call & Number & Percentage \\
\hline Research of place & 85 & 24,78 \\
Research of place and MEDEVAC & 67 & 19,53 \\
MEDEVAC only & 46 & 13,41 \\
Consultation + MEDEVAC & 56 & 16,32 \\
Transport for assessment & 29 & 8,45 \\
Transport for return home & 16 & 4,66 \\
SOS Consultation and MEDEVAC & 15 & 4,37 \\
Transport for admission & 14 & 4,08 \\
Transport for consultation & 11 & 3,20 \\
Advice and information & 343 & 0,58 \\
Transport airport and MEDEVAC & 1 & 0,29 \\
Death during transport & 2 & 1 \\
\hline
\end{tabular}

Table 4 Repartition according to means of transport

\begin{tabular}{lll}
\hline Means of transport & Number & Percentage \\
\hline EMS Dakar & 192 & 55,97 \\
EMS Saint-Louis & 17 & 4,95 \\
Regional Hospital Ambulance & 21 & 6,12 \\
District Ambulance & 25 & 7,28 \\
BNSP & 1 & 0,29 \\
«SOS Médecin » & 2 & 0,58 \\
No transport & 85 & 24,78 \\
Total & 343 & 100 \\
\hline
\end{tabular}

BNSP: National Fire Brigad EMS: Emergency medical services
Table 5 Repartition according to place of intervention

\begin{tabular}{lcc}
\hline Place of intervention & Number & Percentage \\
\hline Home & 110 & 32,06 \\
Health centers & 88 & 25,65 \\
Regional hospital & $6 \mathrm{I}$ & 17,78 \\
Clinics & 46 & $13,4 \mathrm{I}$ \\
Teaching Hospitals & 29 & 8,45 \\
Airports & 9 & 2,62 \\
EMS center & $\mathrm{I}$ & 0,29 \\
Total & 343 & 100 \\
\hline
\end{tabular}

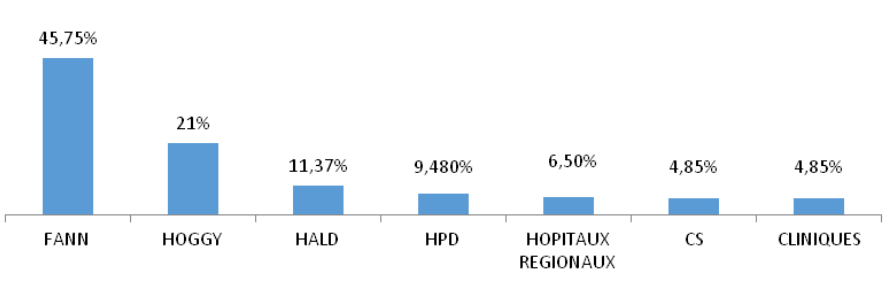

Figure 3 Repartition according to care facilities.

\section{Discussion}

We noticed a male predominance in our study $(54.22 \%)$ which was identical to the work done by Pichard ${ }^{1}$.

These different results show a slight male predisposition even if this difference is not too significant. In our series, $50 \%$ of the patients were over 65 years old. These results are inferior to data in developed countries ${ }^{2}$ where patients over the age of 65 who had a stroke represented $75 \%$. That means that in Senegal, strokes affect old people as well as young ones. ${ }^{8,9}$

Dakar represented $79.30 \%$ of our patients' provenance and this is due to the fact that Senegal has only two EMS located in Dakar and Saint Louis; other regions not having one yet.

The dominant neurologic sign was the hemicorporeal deficit $(51.31 \%)$. The same observation was found by Ndiaye ${ }^{10}(69 \%)$. Language disorders came second with $16 \%$ of the cases; identical to the Keita series. ${ }^{11}$ Ischemic stroke was more frequent than the hemorrhagic with respectively $61 \%$ and $38 \%$ in our series. This preponderance of ischemia is verified in many studies: Toure ${ }^{12}$ has found $60.2 \%$ of ischemia against $39 \%$ of hemorrhage. Keita ${ }^{11}$ has reported $44.7 \%$ of ischemic lesions against $29.6 \%$ of hemorrhage. Diagana ${ }^{13}$ has noticed $52 \%$ of ischemia against $48 \%$ of hemorrhage. These results can be explained by the polymorphism of the risk factors involved in the formation of arterial occlusions which can lead to ischemia more than hemorrhage. ${ }^{14,15}$

The ECG should be a standard practice before any suspicion of stroke. In the series of Guinard, ${ }^{16} 92 \%$ of the patients had performed it and an atrial fibrillation was found in almost one third of the cases or $28 \%$. In our series, only $17 \%$ of the patients have performed an ECG 
and an atrial fibrillation was found in $30.6 \%$. Atrial fibrillations are major providers of ischemic stroke, so the ECG should be systematic before any suspicion of stroke for an early anticoagulant treatment.

The complications found in our study were essentially conscience disturbances like coma with a Glasgow score of less than 8 in $13.41 \%$ of cases. Inhalation pulmonary disease and dehydration were found respectively in $4.6 \%$ and $4 \%$ of patients, mainly due to swallowing disorder or care delaying. These complications are factors of bad prognosis as they lengthen the duration of hospitalization and make care difficult. Place research accounted for $24.78 \%$ of interventions. These categories of patients were hospitalized in health facilities or in non-specialized departments or in structures without brain CT-scan or an adequate care using the national EMS for the transfer of patients.

In our series $55.97 \%$ of the patients had been transported by the EMS of Dakar which was the most suitable and best equipped means of transportation than district ambulances or National Fire Brigade for the early care of stroke patients. Home interventions represented almost one third of the intervention sites with $32.06 \%$. The EMS were responding directly after the first warning signs or the call of the accompanying people. Health facilities come second.

The primary interventions in our series were of $35 \%$. They concerned home interventions, at the headquarters of the EMS and in the airports. These patients received EMS first aid prior to their transfer to hospitals. Fann Hospital was the main host structure for our patients $(45.49 \%)$, this is due to the simple fact that it is the only teaching hospital to have a neurology department in Senegal. The other hospitals with intensive care units have also received our patients.

Stroke is an emergency. Most patients in Senegal arrive late enough for treatment. In our series $65.30 \%$ of patients had consulted in a health facility after the first symptoms. Generally, they were evacuated in taxis or non-medicalized ambulances, which can therefore worsen their symptomatology or delay care; these results are similar to Doumbia's ${ }^{17}$ in Côte d'Ivoire, where the main means of evacuation was non-medical $(86.9 \%)$. We also notice that EMS arrived on average in 15 min after a distress call in Dakar-centre. In the suburbs or outskirts, the average time was $26 \mathrm{~min}$. This is usually due to the numerous traffic jams and the difficult access of some suburbs. In contrast, De-croix ${ }^{18}$ found that the EMS took 60 min to arrive on the intervention sites in the Iles-de-France, which seems long regarding the results of our series.

In the health facilities, the EMS spent a mean time of $34.35 \mathrm{~min}$, while at home it spent much more time (mean time $43.75 \mathrm{~min}$ ). This is understandable, considering the fact that interventions in health facilities were secondary interventions, meaning that the diagnosis is generally known and the initial care already made. The transportation time from the intervention site to the host hospital was $27 \mathrm{~min}$ in the series of De-croix ${ }^{18}$ while in ours this time was $32 \mathrm{~min}$. This quite long time was due essentially to the difficulty of finding place and carrying out a brain CT-scan, to this were added the financial problems.

The interest of national EMS regulation is to address the right patient to the right place and under the right conditions and reduce intra-hospital time delays..$^{19}$ This article also reminds that stroke is not limited to cerebral infarctions, but that rapid care is also necessary in spontaneous cerebral hemorrhages that also benefit from stroke care in specialized unit, blood pressure decrease, coagulation correction and in rare cases surgery. ${ }^{19}$
Finally, it should be noted that the delay for imaging is shorter for EMS patients (mean time $110 \mathrm{~min}$ ) against $160 \mathrm{~min}$ when passing by the emergency department according to the study conducted by Freys. ${ }^{20}$ The Medical Regulator of the 15 th will also organize the hospital reception and promote the fast circuit with the direct arrival to the imaging. Apart from situations corresponding to obvious contraindications (severity, constitutional susceptibility, prior autonomy), indications of intubation and artificial ventilation should remain wide, especially in pre-hospital. This would limit decease and other complications. ${ }^{20}$

Among the patients transported by the EMS, only 10 patients $(4.80 \%)$ had benefited from an orotracheal intubation due to neurological complications (Glasgow score of 8 or less), that is minimal considering the total number of patients presenting complications. All the CT-scan were performed in less than $3 \mathrm{~h}$ after the onset of first symptoms or a mean of $86 \mathrm{mn}$ hence the interest of thrombolysis. No patient had benefited from thrombolysis in our study.

The interest of thrombolysis is to reduce the care time-delay and the deficits sequelae of ischemic stroke. The arterial recanalization performed in a short time, less than $3 \mathrm{~h}$, has widely shown its efficiency decreasing by $20 \%$ the deficits sequelae, ${ }^{21}$ but without impacting the mortality, because of the cerebral hemorrhagic risks of this treatment.

The efficiency of thrombolysis is directly correlated to the precocity of its administration. ${ }^{18}$ Despite the development of specific host structures, the proportion of stroke patients treated by intravenous thrombolysis is inferior to 5\% in France..$^{22,23}$

In our study, $61 \%$ of our patients suffered from ischemic stroke and were seen in less than $3 \mathrm{~h}$ or $1 \mathrm{~h} 26 \mathrm{~min}$ after the onset of first symptoms hence the interest of a thrombolysis out of the contraindications. But the lack of specialized units and the unavailability of thrombolysis drugs are the main reasons of the lack of thrombolysis in Senegal

\section{Conclusion}

Stroke is a major public health problem. Difficulties are sometimes encountered in the care and the research of an appropriate host structure. The purpose of the pre-hospital care is to intervene as soon as possible while making a clinic diagnosis by performing forthwith a brain CT-scan in order to optimize the care and improve the prognostic of stroke patients.

\section{Acknowledgments}

None.

\section{Conflicts of interest}

The authors declare no conflicts of interest.

\section{References}

1. Pichard Fanny. AVC ischémique au CHU de St Pierre de la Réunion en 2013: diagnostic des dysfonctionnements et réflexions sur l'optimisation de la prise en charge précoce.

2. Société Française de Neurovasculaire.

3. NINDS. Stroke study group. Tissue plasminogen activator for acute ischemic stroke, The National Institute of Neurological Disorders and Stroke, rt-PA Stroke study group. N Engl Med. 1995;333(24):15811587. 
4. Circulaire DHOS/DGS/DGAS n 2003-517 du 3 novembre 2003 relative à la prise en charge des accidents vasculaires cérébraux.

5. Fery-Lemonier E. La prévention et la prise en charge des AVC en France: rapport à madame la Ministre de la Santé et des Sports. 2009.

6. Tessier C, Sar. Module de neuro-réanimation. Beaujon 2007-2008.

7. Wolf PA, Kannel WB, Mc GEE DL. Prevention of ischemic stroke: risk factor. In:Barnett HJ, Stein BM, Mohr JP, Yatsu FM, eds. Stroke, pathophysiology, diagnosis and management. New York: Churchill Livingstone; 1986. p. 967-988.

8. Yasaka $\mathrm{M}$, Otsubo $\mathrm{R}, \mathrm{OE} \mathrm{H}$, et al. Is stroke a paradoxal embolism in patients with patent foramen ovale. Internal medicine. 2005;44 (5):434 438.

9. Sagui E, Mbaye P S, Dubecq C, et al. Ischemic and hemorrhagic strokes in Dakar, Senegal: a Hospital-Basek study. Stroke. 2005;36:1844

10. Ndiaye Mohamadou B. Intérêt de l'ETO dans le diagnostic étiologique des AVC ischémiques. Thèse Med, Dakar. 2006 n²2; p.128-148.

11. Keita AD, Toure M, Diawara A, et al. Aspects épidémiologiques des AVC dans le service de TDM à l'hôpital du point G. Med Trop. 2005;65:453-457.

12. Toure K. Epidémiologie des accidents vasculaires cérébraux à la clinique neurologique du CHU de Fann, Dakar- Sénégal. Dakar medical. 2008;53(2):96.

13. Diagana M, Traore H, Bassima A. Apport de la TDM dans le diagnostic des AVC à Nouakchott, Mauritanie. Med Trop. 2002;62:145.

14. Abou M. Tabac et facteurs de risque des accidents vasculaires cérébraux aux Sénégal. Etude prospective allant de Mars 2009 à Février 2010 portant sur 109 cas au service de Neurologie de Fann.
15. Dioum Sokhna. Les facteurs de risque des accidents vasculaires cérébraux cardio-emboliques. Thèse méd Dakar. 2006;58:91.

16. Guinard A. Caractéristiques, prise en charge et devenir des patients reçus dans le service des urgences pour AVC et non admis un unité neurovasculaire. Étude rétrospective réalisée sur l'année 2011 à l'Hôpital de Toulouse-Rangueil.

17. Doumbia O, Kouame A, Kouassia L. Itinéraire pré- et post-hospitalier des patients présentant un accident vasculaire cérébral (AVC) au Service de neurologie, CHU de Yopougon, et au CHU de Cocody, 2013.

18. Delacroix S, Prost, Philippeau F, et al. Service des urgences, hôpital Fleyriat, Bourg-en-Bresse, France Auteur correspondant. La prise en charge précoce des accidents vasculaires cérébraux. Étude de la « filière AVC ». (Expérience du centre hospitalier de Bourg-en-Bresse).

19. Solene Moulin, Didier Leys. Amélioration de la prise en charge des accidents vasculaires cérébraux : le plus important pourrait être à venir. Presse Med. 2015;44:499-501.

20. Freys Z, Chantegret A, Fournier C. Prise en charge de l'accident vasculaire cérébral (moins de 3 heures) en pré-hospitalier. JEUR. 2006;19:137-142.

21. Giroud M, Chatel M. The management of acute cerebrovascular events in France: a new challenge for Neurology in the organisation of hospital based treatment. Rev Neurol (Paris). 2005;161:6-7:734-737.

22. Bonnaud I, Debiais S, Giraudeau B, et al. G - 12 Causes de non thrombolyse chez les patients avec AVC admis dans les 3 premières heures. Revue Neurologique. 2007;163(4):19.

23. Yameogo P, Millogo A, Zabsonre P. Etude des facteurs de risque et de gravité des AVC chez les noirs africains au Burkina Faso. Méd Trop. 1997;57:147-152. 